\title{
Social presence for different tasks and perceived learning in online hospitality culture exchange
}

\author{
Mei-jung Wang \\ National Kaohsiung University of Hospitality \& Tourism, Taiwan \\ Hsueh Chu Chen \\ Hong Kong Institute of Education, Hong Kong
}

\begin{abstract}
This study utilized online discussion and project construction tasks to determine the extent of social presence and collaborative learning for hospitality culture exchange. The online culture exchange lasted for 6 weeks from September to November 2011. Forty-four English majors from a hospitality college in Taiwan and an institute of education in Hong Kong were matched into 22 pairs to participate in this study. Four student helpers facilitated the project. This study analyses patterns of students' social presence for different tasks and students' perceived learning. The results show that participants were more enthusiastic about self-introduction and travel projects than about article reading and discussion. Moreover, patterns of social presence were significantly different for different tasks. Students' responses to language learning and cultural awareness were positive. Students regarded the project as helpful because it offered them a chance to learn language and culture and promote critical thinking and awareness of different perspectives. Students therefore had the opportunity to interact with others, to articulate their ideas, and to negotiate. In addition, the student helpers were able to train themselves to work under pressure, develop coordinating skills and leadership, and learn to make use of different methods of communication.
\end{abstract}

\section{Introduction}

The ubiquitous hospitality English learning platform (U-help) was constructed in 2008. For an introduction to U-help, please refer to Wang (2009). After the initial implementation, studies were conducted to investigate students' perceptions of how well they acquired a foreign language for specific purposes through the online project construction. Wang (2009) explored the ways in which Internet-based projects using U-help can enhance English language and generic skills among Asian hospitality students. Subsequently, Wang (2010) probed further into online communications and offline interactions between students from two colleges. Wang showed that implementing information communication technology (ICT) tools into blended learning can promote social interaction and engagement among students. At the same time, however, students did not adopt active learning strategies unless assisted.

Projects similar to this one have shown similar successful results in the past, but Wang and Ip (2010), using the same platform, failed to yield positive results. The study involved an international telecollaboration project between Taiwan and Macau. The students faced difficulties during the course, including misaligned academic calendars between the two schools and a decrease in motivation resulting from excessive student workload. To overcome these challenges in this study, the researchers carefully examined the timeline of the participants from the two participating regions, Taiwan and Hong Kong. Students were given an orientation about the purposes and scope of this project and were instructed on how to operate U-help. Finally, four student helpers provided consistent guidance to students for effective interaction.

This cultural exchange project between Taiwan and Hong Kong examined several issues. The first part of this project explored university students' emotions and trust levels resulting from collaborative communication (Wang \& Chen, 2012). The current study is the second in a series of experiments to explore social presence relative to different tasks and to quantify the perceived learning in an online hospitality culture exchanges. As Lowenthal (2010) states, researchers should use multiple and mixed methods to investigate how social presence manifests and changes in different contexts, because different kinds of tasks may induce different kinds of social presence. In the previous studies, manipulation of 
different tasks to examine the social presence was relatively limited (Yoo \& Alavi, 2001). Through the presentation of different tasks, we can better understand the nature of social presence and the gains in students' learning. To enhance student-centred learning, decrease teachers' workload, and assess the feasibility of online course implementation, we attempted to investigate the potential role that student helpers may play in promoting interaction and a sense of presence.

\section{Language learning and culture}

Language and culture are intertwined, and each affects the other. Language reflects the culture in the minds of its speakers; culture denotes language and is an integral component within countries' economic, religious, and philosophical systems (Kuo \& Lai, 2006). Culture is a way of life (Condon, 1973) and includes ideas, customs, skills, arts, and tools that give a group of people its characteristics over a given period of time (Saluveer, 2004). Culture is also a matter of habit that evolves into traditions over time, and tradition gives rise to culture (Kuo \& Lai, 2006). Meanwhile, language is a society's primary method of communication, including the communicating of culture. Humans communicate ideas and feeling with each other, and they learn, act out, transmit, and preserve culture through communication (Wang, Lin, \& $\mathrm{Chu}, 2010)$. Language is unique among cultural components, however, because it interacts with culture in ways that other components do not. It is both a transmitter of culture and the main tool for the internalization of the culture by the speaker (Young, Sachdev, \& Seedhouse, 2009). Language is at the same time a moulder of culture and an agentive entity, whereby cultural representations are shaped by the language used to express them (Hinkel, 1999).

Patterns of cognition and custom are frequently explicitly coded in language, and the development of a language often influences its associated culture (Li \& Erben, 2007). Thus, the connection between language and culture has been one of the main concerns of second language (L2) learning for both teachers and students. For decades there has been disagreement over whether the culture of the target language should be included in L2 learning curricula. Over time, people have come to realize the intertwined relationship between culture and language (Pulverness, 2000). Some researchers emphasize that without the study of culture, teaching L2 is inaccurate and incomplete because "the acquisition of a new language means a lot more than the manipulation of syntax and lexicon" (Genc \& Bada, 2005, p. 73).

To many, L2 learning could be perceived as equal to cultural learning. In order to make substantial gains in L2 learning, understanding a new culture is essential (Kuo \& Lai, 2006). Genc and Bada (2005) found that coursework on culture is beneficial to language skills because it raises cultural awareness, changes attitudes towards native and target societies, and contributes to the teaching profession. They pointed out that culture classes are a critical element of language learning and teaching because they have a great deal to offer to the development of communicative proficiency and other language skills.

\section{Social presence}

Social presence is necessary for effective collaboration and knowledge construction, and is important for maintaining a high degree of online social interaction (Kreijns, Kirschner, Jochems, \& van Buuren, 2011; $\mathrm{Tu}, 2001)$. Social presence has been identified as one of the key points to use in addressing the quality of online learning (Rourke, Anderson, Garrison, \& Archer, 2001), and is defined as "the ability of participants in the community of inquiry to project their personal characteristics into the community, thereby presenting themselves to others as 'real people"' (Garrison, Anderson, \& Archer, 2000, p. 94). More recently, Kreijns et al. (2011) have defined social presence as "the degree of illusion that others appear to be a 'real' physical person in either an immediate (i.e., real time/synchronous) or a delayed (i.e., time-deferred/asynchronous) communication episode." Cobb (2009) pointed out that definitions of social presence tend to fall along a continuum, with one end conceptualizing social presence as the degree to which a person is perceived as being "real" and being "there," and the other end focusing on whether there is an interpersonal emotional connection between communicators. Cobb concluded that the majority of researchers place themselves somewhere in the middle of the spectrum, with some emphasis on an emotional connection.

Recognizing the critical role of interaction among participants in learning, researchers and practitioners frequently use the theory of social presence to investigate how people socially interact in online learning environments (Lowenthal, 2010). Different approaches have been adopted to measure social presence. 
For example, Gunawardena and Zittle (1997) developed a social presence measure (GZ Social Presence Scale) to evaluate computer conferences and assess student responses to computer mediated communication. They found that social presence is a strong predictor of student satisfaction. Viewed within Rourke et al.'s (2001) framework, social presence includes three categories of indicators; affective responses, cohesive responses, and interactive responses. Through analysis of the content of the communication within the learning environment, this study shows that social presence manifests itself through interactions among students and instructors. Rourke and the co-researchers thus recommend the use of specific teaching strategies to foster presence. Tu (2001) also noted the relationship between perceived presence and success in online courses, and identified three dimensions of course design which influenced the development of social presence theory; social context, social processes, and interactivity.

In addition to being of critical importance to the level of learner participation and the success of online collaboration, social presence influences the quality of the online learning experience from the student's perspective (Cobb, 2009; Kehrwald, 2008). Picciano's (2002) study supports a strong relationship between students' perception of interaction and their perceived learning. Swan and Shi's (2005) study also found strong relationships between the perceived social presence of peers and perceived learning. In a review of recent research on the role of student group cohesiveness and interaction in team effectiveness in online graduate management education, Garrison and Arbaugh (2007) confirm a strong relationship between social presence and learning outcomes, and regard the social presence construct as crucial to understanding online learning.

Considering the increasing number of online learners, more online learning research should be conducted. For example, Richardson and Swan (2003) call for research to determine how perceptions of social presence influence student satisfaction and students' actual cognitive and affective learning. Similarly, Lowenthal (2010) states that researchers should use multiple and mixed methods to investigate how social presence manifests and changes in different contexts. Moreover, Belz (2003) suggested that Internetmediated intercultural foreign language education should be increased to advocate linguistically critical interpretations of the development of intercultural competence in telecollaboration.

In the global village, mutual understanding among people from different cultural backgrounds is an essential issue. There is a need for additional research to compare the social presence displayed for different tasks in an online learning context and to investigate the potential assistance demonstrated by the student helpers in facilitating these online projects. We sought to address these issues by posing the following research questions:

- What are the impacts of task types on social presence?

- What is students' perceived learning of the hospitality culture exchange project?

\section{Method}

\section{Participants}

The study was conducted during the fall semester of 2011. A hospitality college in Taiwan and an educational institute in Hong Kong each offered 22 students the opportunity to participate in this study. The 44 students who enrolled in the study were matched into 22 pairs. All students participated in this online project voluntarily. All 22 participants in the Taiwan group (aged 18-20) were students in the Department of Applied English. Once a week, they met after one of their English classes, and the researcher checked their work. Participants from Hong Kong were all students of the Department of English (aged 19-22). A 90-minute briefing session was conducted to introduce students to the purpose of the project and the operational procedures of the online platform. The students in Hong Kong were not all in the same class, so they did not meet once a week as the Taiwanese participants did; however, they received reminders and necessary technical support from student helpers when necessary. Four of the subjects (two from each group) were designated student helpers assigned to send weekly reminders, check the progress of the project, and offer timely responses to solve technical problems in order to constantly guide students for effective interaction.

\section{Instruments}


This project used two instruments: content analysis and a survey. The framework of Rourke et al. (2001, p. 10) was adopted because it was designed to explore the nature of interaction in computer mediated communication (CMC) environments and has been used in many studies related to online social presence (Rourke et al., 2001, p. 10). In this study, we used a "thematic unit" as the unit for analyses.

The other instrument employed in this study was a survey designed by the researchers to investigate perceived learning. Of the 15 items in the survey, the first 14 made use of a five-point Likert scale. Items $1,3,5,7$, and 8 were related to how the web-based project promoted English learning, while items 2, 4, and 6 were concerned with whether students benefited from asynchronous hospitality culture exchange. Items nine to fourteen focused on the effects of the different tasks used for this project, including online reading, discussion, and web-based project construction. The open-ended question included at the end elicited students' responses towards perceived learning in the process of hospitality culture exchange. The reliability of the questionnaire employed in the present study is 0.93 using Cronbach's alpha coefficient of internal consistency. The values reached the satisfactory level $(\geq 0.7)$, according to Nunnally and Bernstein (1994).

\section{Procedures}

The 6-week project of online collaborative learning lasted from September to November 2011, as presented in Table 1. The timeline was checked by the two researchers to make sure that there were no misalignments of the academic calendars, including holidays or examination. Students first read articles online about hospitality culture and then discussed the articles on the blogs. After they finished all of the reading selections, each pair was required to do an online project in which they designed a three-day tour of Taiwan and Hong Kong (Figure 2).

Table 1

The content of a 6-week project of online collaborative learning

\begin{tabular}{|c|c|}
\hline Time & Contents \\
\hline Week 1 (Sept. 26-30) & (a) Students (Ss) register and learn the process of the study. \\
\hline Orientation & $\begin{array}{l}\text { (b) Ss answer pre-questionnaires online. } \\
\text { (c) Ss briefly introduce themselves and write a short description of their } \\
\text { partner's city. }\end{array}$ \\
\hline Week 2 (Oct. 3-7) & $\begin{array}{l}\text { Ss read the first article and then complete the online pair discussions. } \\
\text { Articles } 1 \& 2 \text { : Food \& Beverage Culture in Hong Kong/Taiwan. }\end{array}$ \\
\hline Week 3 (Oct. 10-14) & $\begin{array}{l}\text { Discussion question: What are the similarities and differences between food } \\
\text { and beverage culture in Hong Kong and Kaohsiung? } \\
\text { Ss read the second article and then complete the online pair discussion. } \\
\text { Articles } 3 \& 4 \text { : The Top } 10 \text { Hong Kong/Taiwan Destinations among Foreign } \\
\text { Tourists. }\end{array}$ \\
\hline Week 4 (Oct. 17-21) & $\begin{array}{l}\text { Discussion question: What are your favourite night-market snacks, and why? } \\
\text { Each pair writes their pair project (a three-day tour of Taiwan and Hong } \\
\text { Kong). }\end{array}$ \\
\hline Week 5 (Oct. 24-28) & Each pair publishes their pair project online. \\
\hline Week 6 (Oct. 31-Nov. 4) & Ss answer post-questionnaires online. \\
\hline
\end{tabular}




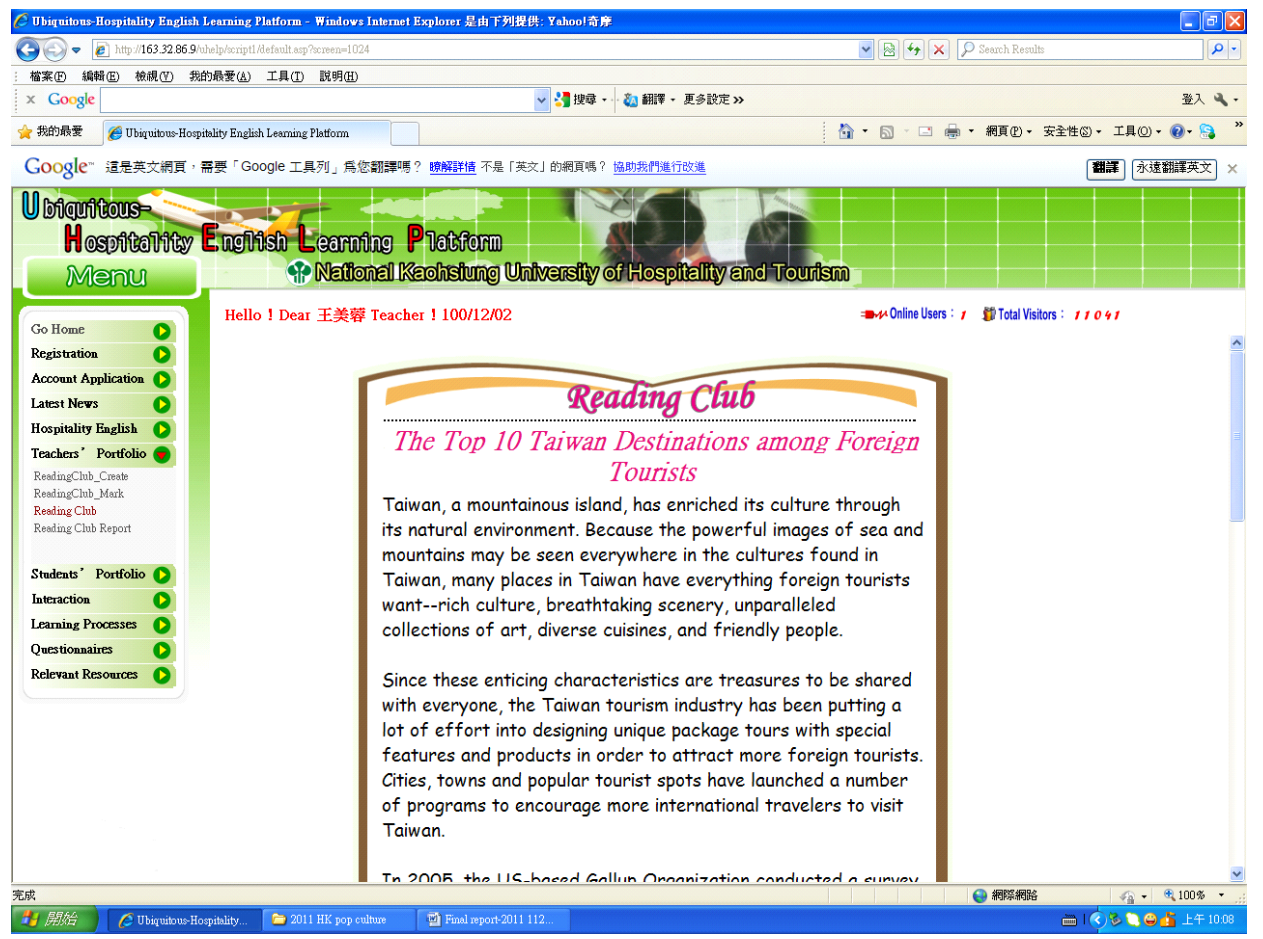

Figure 1. Sample reading article in U-help.

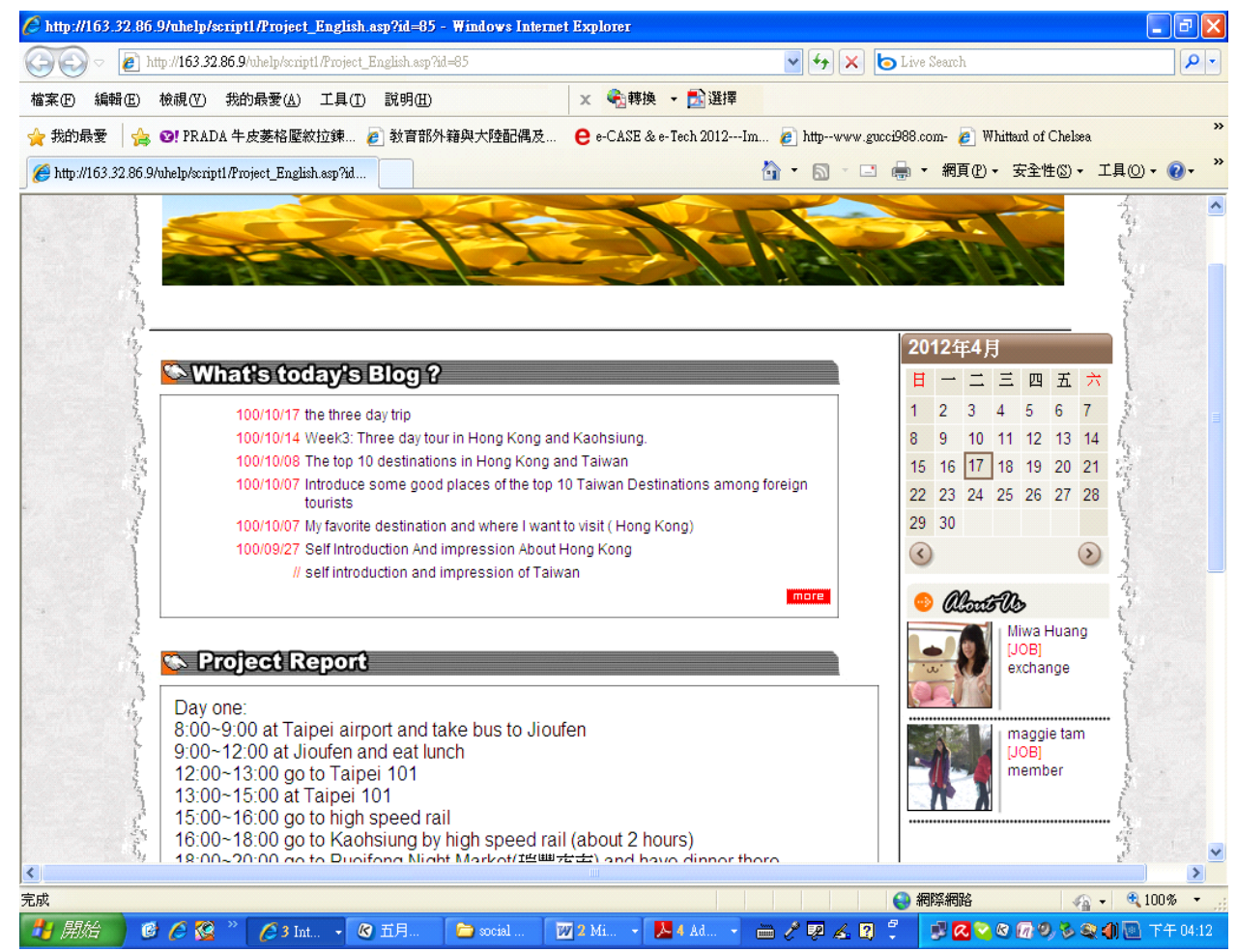

Figure 2. Blog and project in U-help.

\section{Data analysis}

The collected data were analysed both qualitatively and quantitatively. The primary data source for the qualitative analysis was the transcripts of interactions among students in the blogs. There were 307 
messages posted during the research period. One of the researchers and her assistant (who had a master's degree in TESOL) coded the messages. The inter-rater reliability was evaluated using Cohen's kappa ( $\kappa)$, which is a chance-corrected measure of inter-rater reliability. The test result showed that the inter-rater reliability between the two coders was $\kappa=0.70$, which may be taken to represent a satisfactory agreement beyond chance level (Capozzoli, McSweeney, \& Sinha, 1999). To assign data to categories, researchers first read the messages, identified the underlying cognitive processes, and then categorized the messages according to Rourke et al.'s (2001) framework.

Regarding the quantitative analyses, 44 copies of the questionnaire were collected at the end of the project. Descriptive analyses were adopted to analyse the data, including the mean and the standard deviation. Moreover, the independent samples $t$-test was used to compare the responses of the two groups of students.

\section{Results and discussion}

\section{Content analyses of blog posts}

This section reports the content analyses of the blog postings from the Hong Kong and Taiwan groups. Table 2 shows that there were a total of 1,475 targeted responses, in which 864 affective, 255 interactive, and 356 cohesive responses were found. The participants were more enthusiastic in discussions involving the self-introduction and travel project than they were for the discussions of the two article readings. Among the four tasks, the participants showed more interest in and responses to the first task, selfintroduction (466 responses), followed by the travel project (383 responses), then reading number two (341 responses), and finally, reading number one (285 responses). Participants gave more affective responses of social presence in the first three tasks $(364,173$, and 249 responses, respectively), whereas they had a more cohesive response of social presence (216 responses) in the final travel project. A chisquare test was performed to determine whether the three categories were equally preferred in each of the four tasks. Preference for the three categories was not equally distributed in the tasks, $\chi^{2}(6, N=1475)=$ $399.102, p<0.01$.

The learners considered the first task, self-introduction, to be the least demanding. Most learners were committed to this project and curious about their partners at the beginning of the project, so a higher level of social presence was expected. As Tu (2001) mentioned, when learners feel more confident, when they are able to make learning choices, and are actively engaged in learning activities, they demonstrate a higher level of social presence. Here, however, learners were not able to maintain their initial level of enthusiasm for the more demanding first reading task, and a U-curve rate of participation appeared. Responses to the first reading task abruptly dropped to 285 (19.3\%) from their first encounter online with their partners. Fortunately, the rate did not continue to decline. Responses to the second reading task climbed up to $341(23.1 \%)$, and the final project advanced to $383(26.0 \%)$. Changes in response rates may be due to the fact that the learners familiarized themselves with the tasks and established their confidence in expressing their own opinions by posting and responding to the reading, and that they took initiative to participate in the collaborative travel project. Because the final week of the project was in the middle of the semester, the participants' course load was much heavier than when the project started. Unsurprisingly, participants' social presence in the final travel project was not as high as it had been in the first topic, self-introduction.

Table 3 shows the weekly frequency of each type of social presence under the four tasks. Within the affective category, participants used "self-disclosure" and "expression of emotions" more than they used humour. Hong Kong participants were more expressive than their Taiwanese counterparts, but Taiwanese participants preferred to self-disclose more than their Hong Kong counterparts. Under the interactive social presence, "continuing a thread" and "asking questions" were shown more frequently than "quoting from others' messages," "referring explicitly to others' messages," "complimenting," "expressing appreciation," and "expressing agreement." Hong Kong participants asked more questions than their Taiwan counterparts while Taiwan participants preferred to "create a thread" more than their Hong Kong counterparts. Under the cohesive category, "addresses or refers to the group" were expressed more often than "vocatives and phatics/salutations." Taiwanese participants used inclusive pronouns more often than Hong Kong counterparts. 
Australasian Journal of Educational Technology, 2013, 29(5).

Table 2

The frequency and percentage of the subjects' social presence

\begin{tabular}{llllll}
\hline Category & $\begin{array}{l}\text { Self- } \\
\text { introduction }\end{array}$ & Reading 1 & Reading 2 & Travel Project & Total \\
\hline Affective & 364 & 173 & 249 & 78 & 864 \\
& $42.1 \%$ & $20.0 \%$ & $28.8 \%$ & $9.0 \%$ & $100.0 \%$ \\
Interactive & 42 & 57 & 67 & 89 & 255 \\
& $16.5 \%$ & $22.4 \%$ & $26.3 \%$ & $34.9 \%$ & $100.0 \%$ \\
Cohesive & 60 & 55 & 25 & 216 & 356 \\
& $16.9 \%$ & $15.4 \%$ & $7.0 \%$ & $60.7 \%$ & $100.0 \%$ \\
Total & 466 & 285 & 341 & 383 & 1475 \\
& $31.6 \%$ & $19.3 \%$ & $23.1 \%$ & $26.0 \%$ & $100.0 \%$ \\
\hline
\end{tabular}

Table 3

Weekly frequency of each category of the subjects' social presence

\begin{tabular}{|c|c|c|c|c|c|c|c|c|}
\hline Category & Indicators & & $\begin{array}{l}\text { Self- } \\
\text { intro }\end{array}$ & $\begin{array}{l}\text { Reading } \\
1\end{array}$ & $\begin{array}{l}\text { Reading } \\
2\end{array}$ & Project & Total & $\begin{array}{l}\text { Grand } \\
\text { Total }\end{array}$ \\
\hline \multirow[t]{6}{*}{ Affective } & \multirow{2}{*}{$\begin{array}{l}\text { Expression of } \\
\text { emotions }\end{array}$} & HK & 46 & 52 & 46 & 29 & 173 & 269 \\
\hline & & TW & 37 & 18 & 24 & 17 & 96 & \\
\hline & \multirow[t]{2}{*}{ Use of humour } & HK & 3 & 1 & 1 & 2 & 7 & 18 \\
\hline & & TW & 2 & 5 & 2 & 2 & 11 & \\
\hline & \multirow[t]{2}{*}{ Self-disclosure } & HK & 79 & 46 & 92 & 16 & 232 & 575 \\
\hline & & TW & 197 & 51 & 84 & 12 & 343 & \\
\hline \multirow[t]{12}{*}{ Interactive } & \multirow{2}{*}{$\begin{array}{l}\text { Continuing a } \\
\text { thread }\end{array}$} & HK & 11 & 9 & 18 & 19 & 57 & 118 \\
\hline & & TW & 9 & 20 & 15 & 17 & 61 & \\
\hline & \multirow{2}{*}{$\begin{array}{l}\text { Quoting from } \\
\text { others' messages }\end{array}$} & HK & 1 & 0 & 1 & 0 & 2 & 2 \\
\hline & & TW & 0 & 0 & 0 & 0 & 0 & \\
\hline & \multirow{4}{*}{$\begin{array}{l}\text { Referring } \\
\text { explicitly to } \\
\text { others' messages } \\
\text { Asking questions }\end{array}$} & HK & 0 & 1 & 0 & 4 & 5 & 16 \\
\hline & & TW & 2 & 4 & 3 & 2 & 11 & \\
\hline & & HK & 11 & 10 & 13 & 18 & 52 & 85 \\
\hline & & TW & 5 & 6 & 8 & 14 & 33 & \\
\hline & \multirow{4}{*}{$\begin{array}{l}\text { Complimenting, } \\
\text { expressing } \\
\text { appreciation } \\
\text { Expressing } \\
\text { agreement }\end{array}$} & HK & 1 & 0 & 3 & 7 & 11 & 18 \\
\hline & & TW & 1 & 1 & 1 & 4 & 7 & \\
\hline & & HK & 1 & 1 & 3 & 2 & 7 & 16 \\
\hline & & TW & 0 & 5 & 2 & 2 & 9 & \\
\hline \multirow[t]{6}{*}{ Cohesive } & \multirow[t]{2}{*}{ Vocatives } & HK & 3 & 1 & 2 & 5 & 11 & 18 \\
\hline & & TW & 3 & 0 & 1 & 3 & 7 & \\
\hline & \multirow{4}{*}{$\begin{array}{l}\text { Addresses or } \\
\text { refers to the group } \\
\text { using inclusive } \\
\text { pronouns } \\
\text { Phatics/salutations }\end{array}$} & HK & 4 & 22 & 6 & 100 & 132 & 279 \\
\hline & & TW & 15 & 23 & 12 & 97 & 147 & \\
\hline & & HK & 10 & 7 & 0 & 6 & 23 & 59 \\
\hline & & TW & 25 & 2 & 4 & 5 & 36 & \\
\hline \multicolumn{3}{|l|}{ Total } & 466 & 285 & 341 & 383 & 1475 & 1475 \\
\hline
\end{tabular}


Table 4 shows that among the top five indicators, 269 "expressions of emotions" and 575 "selfdisclosures" under the affective category were used, whereas 118 "continuing a thread" and 85 "asking questions" under the interactive category were found. Two hundred seventy-nine "addresses or refers to the group using inclusive pronouns" were found in the cohesive category. Compared to other indicators across all four tasks, "self-disclosure" was used most frequently in the first three tasks, while "addresses or refers to the group using inclusive pronouns" was used more often in the travel project. Differences in the use of various indicators can be linked to the different natures of the tasks.

Participants in Hall and Herrington's (2010) study lacked affective responses, meaning that "there were no intimacy behaviours that were needed to provide the social presence to develop or maintain a learning community (pp. 1022-23)." Hall and Herrington suggested that an orientation session was needed to "help participants know each other sufficiently to overcome barriers for sharing at a personal level." In the current study, we did not conduct a face-to-face briefing session for both parties because they were from two different areas - one from Hong Kong and the other from Taiwan. Instead, we chose self-introduction as the first topic to facilitate intimacy. The students in this study used affective language and selfdisclosure to develop an online social identity. They created warmth and feelings of belonging at the beginning of the project, and thus were willing to participate and contribute their ideas across the process. We believe the sense of belonging is one of the key factors that facilitate the development of an effective online community, and that this helped lead to the successes found in this current project.

Table 4

Most frequently used indicators in four tasks

\begin{tabular}{lllllll}
\hline Category & Indicators & Self-intro & Reading 1 & Reading 2 & Project & Total \\
\hline Affective & $\begin{array}{l}\text { Expression of } \\
\text { emotions }\end{array}$ & 83 & 70 & 70 & 46 & 269 \\
Self-disclosure & 276 & 97 & 176 & 28 & 575 \\
Interactive & $\begin{array}{l}\text { Continuing a } \\
\text { thread }\end{array}$ & 20 & 29 & 33 & 36 & 118 \\
$\begin{array}{l}\text { Asking questions } \\
\text { Cohesive }\end{array}$ & 16 & 16 & 21 & 33 & 85 \\
& $\begin{array}{l}\text { Addresses or } \\
\text { refers to the group } \\
\text { using inclusive } \\
\text { pronouns }\end{array}$ & 19 & 45 & 18 & 197 & 279 \\
\hline
\end{tabular}

Some examples of indicators used across the four tasks are listed below. Under the affective category, the students used conventional expressions of emotions and unconventional expressions of emotions including repetitious punctuation (e.g., !!!) and emoticons (e.g., $\wedge \wedge$ ). Additional excerpts come from participants HK08 and TW05, who presented details of life outside of class. These responses showed affective examples via the indicator of self-disclosure.

1. Since my secondary school time, I have been fascinating in listening to Taiwan singers' songs and watching drama series in Taiwan. (HK 08 in self-introduction)

2. I want to go around the world as I can, so I study Applied English in my senior high school that I can talk to people from other countries. (from TW05 in self-introduction)

Some typical examples of "continuing a thread" and "asking questions" (which belong to the interactive category) are set forth below. Because the indicator "continuing a thread" is a software dependent feature, the print-screen page showing three replied messages from participants CC and YY is demonstrated in Figure 3. 


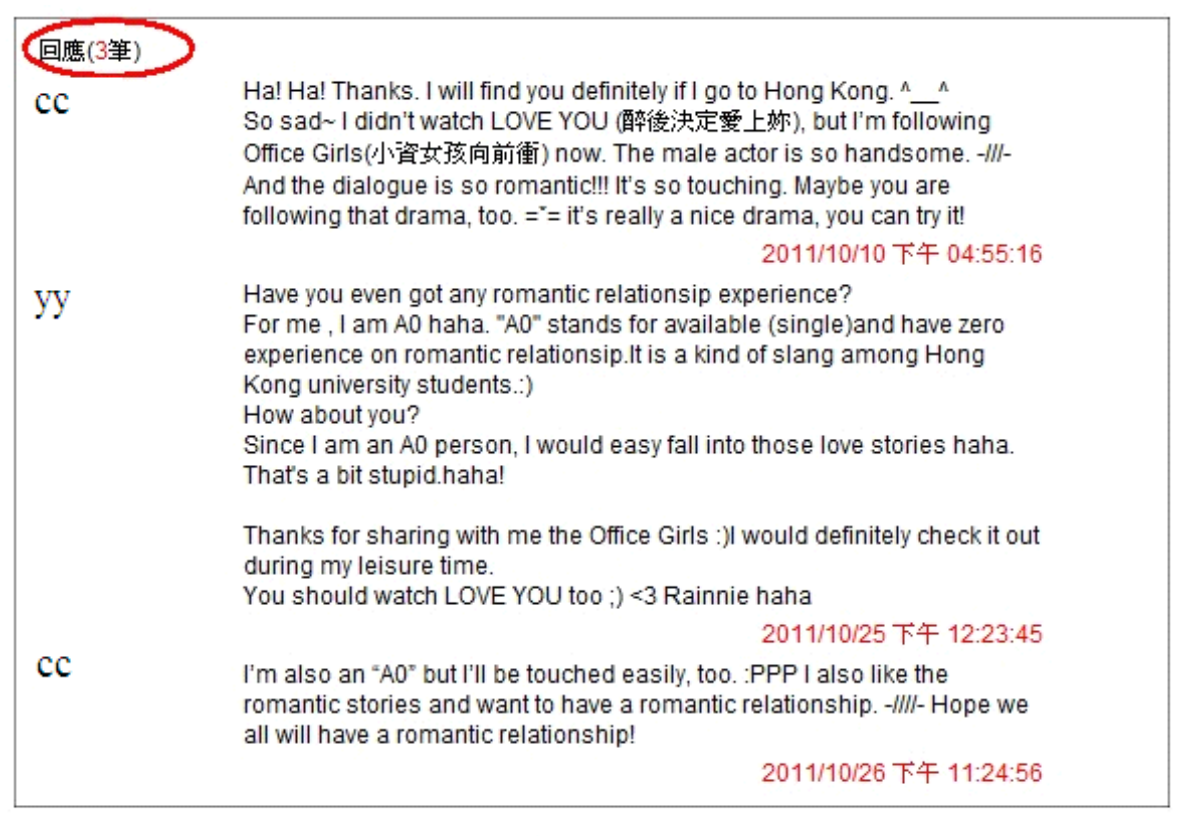

回應此Blog

Figure 3. Sample page three replied messages from participants CC and YY.

Another excerpt was extracted from participant HK01, who asked the following question: Is there any street dance in Taiwan? (from HK01 in Reading 2).

Two examples from the travel project demonstrate the cohesive category. The first example was extracted from participant HK07. This response gave a cohesive example via the indicator of vocatives, "addressing or referring to participants by name." The second example comes from participant TW03. The response is an example of "addressing the group using inclusive pronouns."

1. Ash $\backslash\left(\wedge^{\wedge} \mathrm{O}^{\wedge}\right) /$ you always have great insight in every blogs! (from HK07)

2. Because we need to have some common view, I combine your schedule with mine. (from TW03)

Next, students' responses to cultural awareness and reflection in the blog posts were also observed. Two excerpts are listed below:

Many people think pearl milk is delicious, but I don't really think so. There are more kinds of beverages in Taiwan that maybe you have not heard. If you have a chance come to Taiwan, don't forget ask me where is worth visiting (from TW15 in Self-introduction)

In the above excerpt, the Taiwan participant found that many people overseas think that pearl milk tea is representative of a typical beverage in Taiwan, but she does not think that is accurate. A cultural recognition discrepancy exists between the two parties. Such cultural stereotypes could be addressed or even reduced through this kind of cultural exchange.

As an English major student who has been to Taiwan, I believe this is a valuable chance to interact with Taiwan students and exchange our opinions. Through our discussions, I hope to know more about Kaohsiung as well as introducing Hong Kong's food and culture to you and your peers in return. Local people know more about the parts which foreigners or visitor may overlook. Therefore hopefully I can understand more about Taiwan this beautiful place. (from HK08 in Self-introduction)

The above is a reflection from a Hong Kong participant. Through language interacting with culture in this way, the program provided the opportunity for him to bring new understanding to his own culture and to share his culture with his partner. It also raised his awareness and consciousness about the friends from 
his neighbourhood, from China, Asia, or even western countries. It also taught him to respect the role of language, which is both a transmitter of culture and the main tool for the internalization of culture.

Comparing the above results with those found in Wang and Ip (2010), it can be concluded that this study did not suffer from the challenges resulting from the misalignment of academic calendars, decreasing of motivation resulting from student workload, or tensions between the instructors. The participants in this study had low dropout rates and high retention, as shown by the frequency of their social presence. Those factors, in turn, had a positive effect on the instructors' personal and professional satisfaction and selfesteem without tensions being aroused between the instructors, as described by Saiz (2005). In addition, participants in this study seemed to be able to adopt appropriate online communication skills and utilize different CMC systems effectively, which helps to enhance online social presence and the goals of this project (Tu, 2001). Consequently, and in contrast with previous finding (e. g., Cross \& Hitchcock, 2006), the Chinese students in this study were willing to speak in a public forum that is the communicative approach favoured by western teachers of the English language.

\section{Survey on perceived learning in online hospitality culture exchanges}

The survey used in this study included 14 five-point Likert type items. Each item was divided into two rows, with the top row marked "HK" for Hong Kong participants and the bottom marked "TW" for Taiwanese students (as shown in Table 5). Percentages for each scale, the mean, the standard deviation, and the $t$ values were then calculated. Responses of "strongly agree" and "agree" were consistently summed. Participants in Hong Kong gave similar responses to the first two items, regarding whether the web-based project enhanced English learning efficiency and critical thinking abilities. The range of responses for these same items was wider for Taiwanese participants, some of whom strongly agree that their English learning efficiency and critical thinking abilities improved. Fewer Taiwanese students had "no comment," and the mean values for the Taiwanese groups were slightly higher for item one and item two. Significant differences were observed for item three when participants were asked if the project promoted different perspectives of thinking. Of the Hong Kong group, 68.8\% answered that the project did promote different perspectives, while the Taiwanese participants were significantly more positive, with $93.8 \%$ agreeing with the statement. 
Table 5

Results of surveys

\begin{tabular}{|c|c|c|c|c|c|c|c|c|c|}
\hline & Group & $\begin{array}{l}\text { Strongly } \\
\text { Agree }\end{array}$ & Agree & $\begin{array}{c}\text { No } \\
\text { comment }\end{array}$ & Disagree & $\begin{array}{l}\text { Strongly } \\
\text { disagree }\end{array}$ & $M$ & $S D$ & $t$ \\
\hline \multirow{2}{*}{$\begin{array}{l}\text { I think this web-based project helps me learn English } \\
\text { more efficiently. }\end{array}$} & HK & - & 68.8 & 25 & 6.3 & - & 3.63 & .62 & \multirow{2}{*}{-.47} \\
\hline & TW & 12.5 & 62.5 & 12.5 & 12.5 & - & 3.75 & .86 & \\
\hline \multirow{2}{*}{$\begin{array}{l}\text { I think this web-based project enhances my critical } \\
\text { thinking ability. }\end{array}$} & HK & - & 68.8 & 18.8 & 12.5 & - & 3.56 & .73 & \multirow{2}{*}{-1.27} \\
\hline & TW & 18.8 & 68.8 & 6.3 & - & 6.3 & 3.94 & .93 & \\
\hline \multirow{2}{*}{$\begin{array}{l}\text { I think this web-based project helps me promote different } \\
\text { perspectives of thinking. }\end{array}$} & HK & - & 68.8 & 18.8 & 12.5 & - & 3.56 & .73 & \multirow{2}{*}{$-2.20 *$} \\
\hline & TW & 25 & 68.8 & - & 6.3 & - & 4.13 & .72 & \\
\hline \multirow{2}{*}{$\begin{array}{l}\text { I think this web-based project increases my interaction } \\
\text { with students in other schools. }\end{array}$} & HK & 18.8 & 62.5 & 18.8 & 0 & - & 4.00 & .63 & \multirow{2}{*}{.37} \\
\hline & TW & 43.8 & 18.8 & 18.8 & 18.8 & - & 3.88 & 1.20 & \\
\hline \multirow{2}{*}{$\begin{array}{l}\text { I think this web-based project increases the opportunities } \\
\text { for me to learn English }\end{array}$} & $\mathrm{HK}$ & - & 87.5 & 12.5 & - & - & 3.88 & .34 & \multirow[b]{2}{*}{-.67} \\
\hline & TW & 37.5 & 43.8 & 12.5 & - & 6.3 & 4.06 & 1.07 & \\
\hline \multirow{2}{*}{$\begin{array}{l}\text { I think this web-based project allows me to learn at my } \\
\text { own pace. }\end{array}$} & HK & 6.3 & 75 & 18.8 & - & - & 3.88 & .50 & \multirow{2}{*}{-.22} \\
\hline & TW & 25 & 56.3 & 12.5 & - & 6.3 & 3.94 & 1.00 & \\
\hline \multirow{2}{*}{$\begin{array}{l}\text { I think this web-based project promotes my motivation to } \\
\text { learn English. }\end{array}$} & $\mathrm{HK}$ & 6.3 & 62.5 & 31.3 & - & - & 3.75 & .58 & \multirow[b]{2}{*}{.21} \\
\hline & TW & 18.8 & 43.8 & 31.3 & - & 6.3 & 3.69 & 1.01 & \\
\hline \multirow{2}{*}{$\begin{array}{l}\text { I think this web-based project increases students' interest } \\
\text { in learning English. }\end{array}$} & HK & - & 81.3 & 18.8 & - & - & 3.81 & .40 & \multirow{2}{*}{.56} \\
\hline & TW & 12.5 & 50 & 31.3 & 6.3 & - & 3.69 & .79 & \\
\hline \multirow[t]{2}{*}{ Online reading helps me learn English more efficiently. } & HK & - & 75 & 12.5 & 12.5 & - & 3.63 & .72 & \multirow{2}{*}{-.23} \\
\hline & TW & 12.5 & 50 & 31.3 & 6.3 & - & 3.69 & .79 & \\
\hline \multirow{2}{*}{$\begin{array}{l}\text { Online reading helps me understand hospitality culture } \\
\text { more efficiently. }\end{array}$} & HK & 12.5 & 50 & 37.5 & - & - & 3.75 & .68 & \multirow{2}{*}{.43} \\
\hline & TW & 18.8 & 37.5 & 31.3 & 12.5 & - & 3.63 & .96 & \\
\hline \multirow{2}{*}{$\begin{array}{l}\text { Web-based discussion helps me learn English more } \\
\text { efficiently. }\end{array}$} & HK & 6.3 & 62.5 & 31.3 & - & - & 3.75 & .58 & \multirow{2}{*}{.64} \\
\hline & TW & 12.5 & 50 & 25 & 6.3 & 6.3 & 3.56 & 1.03 & \\
\hline \multirow{2}{*}{$\begin{array}{l}\text { Web-based discussion helps me understand hospitality } \\
\text { culture efficiently. }\end{array}$} & HK & 18.8 & 50 & 31.3 & - & - & 3.88 & .72 & \multirow{2}{*}{1.25} \\
\hline & TW & 6.3 & 56.3 & 25 & 6.3 & 6.3 & 3.50 & .97 & \\
\hline \multirow{2}{*}{$\begin{array}{l}\text { Web-based project construction helps me learn English } \\
\text { more efficiently. }\end{array}$} & HK & - & 75 & 25 & 0 & - & 3.75 & .45 & \multirow{2}{*}{-.50} \\
\hline & TW & 25 & 43.8 & 25 & 6.3 & - & 3.88 & .89 & \\
\hline \multirow{2}{*}{$\begin{array}{l}\text { Web-based project construction helps me understand } \\
\text { hospitality culture efficiently. }\end{array}$} & HK & 6.3 & 68.8 & 25 & - & - & 3.81 & .54 & \multirow[b]{2}{*}{.25} \\
\hline & TW & 18.8 & 43.8 & 31.3 & 6.3 & - & 3.75 & .86 & \\
\hline
\end{tabular}

hospitality culture efficiently.

TW $\quad 18.8$

68.8

31.3

6.3

3.81
3.75

.86 


\section{ascilite}

More than $80 \%$ of the Hong Kong subjects agreed that the project improved peer communication (as seen in item four) versus $62 \%$ of the Taiwanese subjects. The group in Hong Kong had no negative opinions and $18.8 \%$ of the Taiwanese group chose "disagree". When students were asked if they feel the project increased English learning opportunities or allowed them to learn at their own pace, both groups were again very positive. Over $80 \%$ of both groups agreed with items five and six, and the Taiwanese group had slightly higher percentages for both cases. For item seven, despite $31 \%$ of the participants from both groups stating a neutral stance, over $60 \%$ of both groups agreed that this type of project does promote motivation. As for their interest in English learning, $81 \%$ from the Hong Kong group and $63 \%$ of the Taiwanese group agreed that the project helped increase their interests.

The next items (nine to fourteen) mainly cover the effect of the different tasks used for this project, including online reading, discussion, and web-based project construction. Items nine and ten relate to online reading and whether it helps students learn English and the hospitality culture efficiently. For these two items, both groups had over $60 \%$ positive responses. Similar results were found for the next two items for web-based discussions, with both groups showing over $60 \%$ agreement with the statements. For items thirteen and fourteen on web-based project construction, $75 \%$ of the Hong Kong participants were positive and the other $25 \%$ chose not to comment. Over $60 \%$ of the Taiwan group was positive for both items. The two groups yielded similar mean values.

Generally speaking, the Taiwanese participants expressed their opinions more strongly and choose "strongly agree" more frequently. Both groups choose negative opinions at low frequencies, but "strongly disagree" appeared numerous times from the Taiwan side and was never chosen by the Hong Kong group. We can conclude that the participants demonstrated positive attitudes toward this project and no significant differences were found in terms of the responses to different tasks. With respect to the only significant difference found between participants - regarding the promotion of different perspectives of thinking - this phenomenon might explain why Taiwanese students regard an exchange project as a great chance for them to develop different perspectives of thinking. Regarding why the Taiwanese students expressed stronger positive and negative opinions than the Hong Kong group, one possible explanation for the difference is that, as discussed in the Wang and Chen (2012), the Taiwanese students have had fewer opportunities to explore themselves in such an online learning project. The experiences of culture exchange with students from different regions were new to them. This may explain why they expressed stronger opinions towards the project. On the other hand, most of the Hong Kong participants in this study had either had one-semester immersion experiences in English-speaking countries or attended summer exchange programs in Asian or European countries. It was not a new experience for them to participate in intercultural communication, and this may contribute to their less polarised responses to the survey.

Now, let us turn to the open-ended question, which asked subjects about their perceived learning from the culture exchange project. The results are shown in Table 6 . The most obvious learning outcome perceived by these students is cultural learning, which had twelve mentions--including five from the Hong Kong students and seven from the Taiwanese students. The students were happy to have the opportunity to participate in a brief cultural exchange and to learn the different cultures of these two regions. More specifically, they learned useful information related to tourism and hospitality. The participants also valued the interaction they had shared with one another. They showed great interest in meeting people from other parts of the world, communicating, and making friends. In addition, learning effective methods of communication was a big plus to some students. The third category included learning English. This web-based project provided the participants with more opportunities to use English outside of class. Finally, participants expressed that this project helped them promote different perspectives of thinking. They learned how peers of the same age might think. 
Table 6

Results of perceived learning in open-ended question

\begin{tabular}{|c|c|c|c|c|}
\hline & Total & $\mathrm{HK}$ & TW & \\
\hline 1. Learn more culture & 25 & 14 & 11 & $\begin{array}{l}\text { 1. Very useful cuisine information and a good web- } \\
\text { based project to know my partner's culture, such as } \\
\text { tourist attractions or famous local delicacy. } \\
\text { 2. To know other students in different schools and } \\
\text { understand the different cultures between Kaohsiung } \\
\text { and Hong Kong. }\end{array}$ \\
\hline 2. Interact with others & 12 & 8 & 4 & $\begin{array}{l}\text { Interaction with other parties from different nations. } \\
\text { Learn to communicate with others effectively. }\end{array}$ \\
\hline 3. Learn English & 6 & 2 & 4 & $\begin{array}{l}\text { Learn English more efficiently. } \\
\text { It gives me a chance to practice my English when I } \\
\text { talk to my group mate. }\end{array}$ \\
\hline $\begin{array}{l}\text { 4. Promote different } \\
\text { thinking }\end{array}$ & 5 & 2 & 4 & $\begin{array}{l}\text { 1. Promote different perspectives of thinking } \\
\text { 2. I can know more about people the same age as me } \\
\text { and know more about things in Taiwan. }\end{array}$ \\
\hline
\end{tabular}

Perceived learning is critical for students to develop intercultural communication competence (e.g., Byram, Nicjols, \& Stevens, 2001; Byram \& Kramsch, 2008; Deardorff, 2006) and higher-level thinking ability (e. g., Chen \& Looi, 2007; Murphy, 2004). These competencies are highly valued in the contemporary educational and professional settings. They are also the central goal of this project. As Wang (2009) indicated, the collaborative nature of project work enables students to engage in more profound thinking and provides them with more perspectives. Consequently, students can learn to articulate their ideas and negotiate with others.

\section{Student helpers' reflections}

This project went smoothly as a result of the assistance of the four student helpers, who reflected on the whole process of this project and demonstrated their personal growth with regard to the following three aspects:

\section{Language learning}

One student helper pointed out that he was able to see and study common writing errors by checking group members' work, and that he learned things that were not taught in textbooks. Helpers also found that the participants were nervous and unsure of their own English skills at the beginning of the project, but after the project was finished they were glad that they had taken part. One called his experience both unique and precious. Take the following excerpts as examples.

I need to do my own works and also check other 12 students' articles. However, when I checked the articles, I learned others' writing skills. I saw plenty of interesting usage of terms and the way they think. They definitely have effect my way of writing an essay. (Student helper A)

Being a project assistant is not something new to me. Though all procedures are just familiar to me, what I have learnt and gained through participation in this project are no doubt unique and precious. (Student helper C)

\section{Coordinating skills /Leadership}

Helpers also felt pressure and stress because it was imperative for them to serve as the communication link between students and teachers. Additionally, checking others' homework was felt to be a heavy responsibility. Checking work required bringing forward the professor's messages while at the same time being considerate of students who were busy with other school work. Helpers also sometimes had to motivate the students. One helper stated that students seldom replied to her email reminders about finishing their weekly progress; hence, the email reminding system was felt to not be as effective as expected. The student helpers were appreciative 
of the fact that they learned about communication, were able to help the group members, and made some new friends. The following excerpts illustrate how they learn coordinating skills and leadership.

This project doubtlessly produced a nurturing platform for me to learn to be a successful leader, who coordinated with chief investigators, partners, and teammates for a smooth progress. This work is rewarding not just because I could be trained to be a leader, at the same time, the leader was also an independent problem-solving provider, a cordial coordinator, and an amiable communicator, for both Professors and team members in Taiwan and Hong Kong (Student helper D)

I had to follow the program and write the task in advance and also discover the problem which will happen to us, and notice the members who didn't finish the homework too. Although I didn't do everything with $100 \%$ correct, but I can experience more things that we cannot learn from the book. (Student helper B)

\section{Culture learning}

The student helpers also expressed their gratitude toward acquiring new cultural knowledge and understanding through working with groups of students from Taiwan and Hong Kong. Not only were they able to understand the other's culture better, they were surprised that the project brought them new knowledge of their own culture. Beyond the surface knowledge of food and culture being exchanged, student helpers were able to break down some of the stereotypes they used to hold about the other party and learn about personalities, attitudes, and characteristics of the group members. The following excerpts are instances of perceived culture learning.

Taiwan students also do much better than many of us especially their culture senses and knowledge of their countries. (Student helper C)

After completing the project, I got better knowledge of Taiwan's culture from team members there and as well as Hong Kong's culture, which is out of my expectation; it is fortunately we can share our views with counterparts in Kaohsiung, though we are geographically apart. (Student helper D)

To increase intimacy and immediacy, which are two important factors for an effective online community, student helpers helped participants in the cultural exchange process. Hall and Herrington (2010) suggest that group leaders should be used in online learning to encourage members to build a learning community through effective social presence. The results turned out to be positive. The student helpers not only promoted their own coordinating and communication skills but they also constantly guided the participants for effective interaction. This result is what was expected from using the same platform as Wang's (2010) study with less participant interaction.

\section{Conclusions and suggestions}

The results indicate that the participants were most enthusiastic about the self-introduction and travelling projects. Self-introduction is the least demanding and students' interest was high at the beginning of the project. Social presence then took a drastic drop when students took on more challenging tasks, before rising a bit toward the end of the project. Enthusiasm did not, however, reach the level of the first activity, which was not surprising because students had much heavier workloads at the end of the project than when it started. When asked to give opinions about the project, most students offered positive feedback. They found the project to be helpful in many ways, as it offered them a chance to learn both language and culture. Furthermore, the project promoted critical thinking and thoughts on different perspectives. Students were able to understand themselves and their overseas partners better. They had the opportunity to interact with others, to articulate their ideas, and to negotiate. Participants were fond of the cultural learning and were thrilled to 
make new friends. Those who were student helpers were able to train themselves to work through pressure, develop coordinating skills and leadership, and to learn the effects of different methods of communication.

As Hall and Herrington (2010) mentioned, the social presence required for community development may be promoted by a variety of factors, including teacher immediacy and collaborative tasks, as well as the way the learners use affective language and self-discourse to develop an online social identity. In this study, no teacher presence was involved, but the student helpers played an active role in promoting immediacy. Additionally, both the travel project and the self-introduction task helped establish the community by guiding the learners in completing their collaborative work and developing their social identity. This support led to a higher social presence in this study.

In terms of teaching implications, this study shows ways in which culture can be incorporated into foreign language course materials. Cultural education raises cultural awareness and changes attitudes toward native and target societies. Therefore, culture-integrated classes are highly recommended and we as teachers should put more effort into implementing cultural features in curriculum design. Additionally, through analysis of the content of the communications within the online environment, we found that social presence manifests itself through interactions among students, their peers, and student helpers. The results of the study reveal tips for preparing materials that will foster presence. For example, tasks 1 (self-introduction) and 4 (travel project) facilitated more social presence with affective and cohesive responses than the other two reader-response type of reading tasks. Different kinds of tasks may induce different kinds of social presence. To achieve the goals of the lesson and to promote the expected types of interaction, carefully selecting the tasks in a cultural exchange program is very important. For example, in addition to the use of initial ice-breaker activities for stimulating social presence, collaborative activities such as small group discussions and pair project conduction must be checked and monitored regularly to ensure students' participation and engagement. Whenever the interaction among the participants decreases, teachers or student helpers should provide timely encouragement or support to foster social presence. Consequently, a more socially present online learning environment can be established, and thus more positive perceptions of learning and a greater rate of retention can be achieved.

\section{Acknowledgements}

This paper was supported by the National Science Council in Taiwan [NSC 100-2511-S-328-001- and NSC 101-2410-H-328-005-] and the Centre for Popular Culture and Education of Hong Kong Institute of Education.

\section{References}

Belz, J. A. (2003). Linguistic perspectives on the development of intercultural competence in telecollaboration. Language Learning \& Technology, 7(2), 68-99.

Byram, M., Nicjols, A., \& Stevens, D. (2001). Developing intercultural competence in practice. Multilingual Matters Ltd.

Byram, K., \& Kramsch, C. (2008). Why is it so difficult to teach language as culture? The German Quarterly, $81,20-34$.

Capozzoli, M., McSweeney, L. \& Sinha, D. (1999). Beyond kappa: A review of interrater agreement measures. The Canadian Journal of Statistics, 27(1), 3-23.

Chen, W., \& Looi, C.-K. (2007). Incorporating online discussion in face to face classroom learning: A new blended learning approach. Australasian Journal of Educational Technology, 23(3), 308-327. Retrieved from http://www.ascilite.org.au/ajet/ajet23/chen.html 
Condon, E. C. (1973). Introduction to cross cultural communication. New Brunswick, NJ: Rogers University Press.

Cobb, S. C. (2009). Social presence and online learning: A current view from a research perspective. Journal of Interactive Online Learning, 8(3), 241-254.

Cross, J., \& Hitchcock, R. (2006, July). Differences, difficulties and benefits: Chinese students' views of UK $H E$. Paper presented at the Responding to the Needs of the Chinese Learner in Higher Education: Internationalising the University. Second Biennial International Conference, University of Portsmouth..

Deardorff, D. K. (2006). Identification and assessment of intercultural competence as a student outcome of internationalization. Journal of Studies in International Education, 10(3), 241-266.

Garrison, D. R., \& Arbaugh, J. B. (2007). Researching the community of inquiry framework: Review, issues, and future directions. The Internet and Higher Education, 10(3), 157-172. Retrieved from http://www.sciencedirect.com/science/article/pii/S1096751607000358

Genc, B., \& Bada, E. (2005). Culture in language learning and teaching. The Reading Matrix, 5(1), 73-84.

Gunawardena, C. N., \& Zittle, F. (1997). Social presence as a predictor of satisfaction within a computer mediated conferencing environment. American Journal of Distance Education, 11(3), 8-25.

Hall, A., \& Herrington, J. (2010). The development of social presence in online Arabic learning communities. Australasian Journal of Educational Technology, 26(7), 1012-1027. Retrieved from http://www.ascilite.org.au/ajet/ajet26/hall.pdf

Hinkel, E. (1999). (Ed.), Culture and second language teaching and learning. Cambridge University Press.

Kehrwald, B. (2008). Understanding social presence in text-based online learning environments. Distance Education, 29(1), 89-106.

Kreijns, K., Kirschner, P. A., Jochems, W., \& van Buuren, H. (2011). Measuring perceived social presence in distributed learning groups. Education and Information Technologies, 16(4), 365-381.

Kuo, M.-M., \& Lai, C.-C. (2006). Linguistics across cultures: The impact of culture on second language learning. Journal of Foreign Language Instruction, 1(1), 10pp.

Li, J., \& Erben, T. (2007). Intercultural learning via instant messenger interaction. CALICO Journal, 24(2), 291-311.

Lowenthal, P. R. (2010). The evolution and influence of social presence theory on online learning. In T. T. Kidd (Ed.), Online education and adult learning: New frontiers for teaching practices (pp. 124-134). Hershey, PA: IGI Global.

Murphy, E. (2004). An instrument to support thinking critically about critical thinking in online asynchronous discussions. Australasian Journal of Educational Technology, 20(3), 295-315. Retrieved from http://www.ascilite.org.au/ajet/ajet20/murphy.html

Nunnally, J. C., \& Bernstein, I. H. (1994). Psychometric theory (3rd ed.). New York: McGraw.

Picciano, A. G. (2002). Beyond student perceptions: Issues of interaction, presence, and performance in an online course. Journal of Asynchronous Learning Networks, 6(1), 21-40. 
Pulverness, A. (2000). Distinctions \& dichotomies: culture-free, culture-bound. English Teaching Professional, 14. Retrieved August 25, 2013, from http://www.academia.edu/268755/Distinctions_and_Dichotomies_Culture-Free_Culture-Bound

Richardson, J., \& Swan, K. (2003). Examining social presence in online courses in relation to students perceived learning and satisfaction. Journal of Asynchronous Learning Networks, 7(1), 68-88.

Rourke, L., Anderson, T., Garrison, D. R., \& Archer, W. (2001). Assessing social presence in asynchronous, text-based computer conferencing. Journal of Distance Education, 14(3), 51-70.

Sáiz, F. B. (2005). Online learners' frustration. Implications for lifelong learning. Proceedings of the EDEN 2005 Annual Conference, Finland, 500-507. Retrieved from www.edenonline.org/system/files/Annual_2005_Helsinki_Proceedings.pdf

Saluveer, E. (2004). Teaching culture in English classes. Unpublished master's thesis, University of Tartu, Estonia.

Swan, K., \& Shih, L. F. (2005). On the nature and development of social presence in online course discussions. Journal of Asynchronous Learning Networks, 9(3), 115-136.

Tu, C. H. (2001). How Chinese perceive social presence: An examination of interaction in an online learning environment. Educational Media International, 38(1), 45-60.

Wang, M. J. (2009). Web based projects enhancing English language and generic skills development for Asian hospitality industry students. Australasian Journal of Educational Technology, 25(5), 611-626. Retrieved from http://www.ascilite.org.au/ajet/ajet25/wang.pdf

Wang, M. J. (2010). Online collaboration and offline interaction between students using asynchronous tools in blended learning. Australasian Journal of Educational Technology, 26(6), 830-846. Retrieved from http://www.ascilite.org.au/ajet/ajet26/wang.pdf

Wang, M. J., \& Ip, K. I. (2010). Tasks and challenges faced by teachers in handling an online project. Asian EFL Journal, 12(4), 143-158.

Wang, M. J., \& Chen, H. C. (2012). Emotions and pair trust in asynchronous hospitality cultural exchange for students in Taiwan and Hong Kong. The Turkish Online Journal of Educational Technology, 11(4), 119131.

Wang, W. C., Lin, C. H., \& Chu, Y. C. (2011). Cultural diversity and information and communication impacts on language learning. International Education Studies, 4(2), 111-115.

Yoo, Y., \& Alavi, M. (2001). Media and group cohesion: relative influences on social presence, task participation, and group consensus. MIS Quarterly, 25(3), 371-390.

Young, T., Sachdev, I., \& Seedhouse, P. (2009). Teaching and learning culture on English language programmes: a critical review of the recent empirical literature. Innovation in Language Learning \& Teaching, 3(2), 149-169. 
Corresponding author: Mei-jung Wang, sebrinajoy@yahoo.com.tw

Australasian Journal of Educational Technology (C) 2013.

Please cite as: Wang, M.-J., Chen, H. C. (2013). Social presence for different tasks and perceived learning in online hospitality culture exchange. Australasian Journal of Educational Technology, 29(5), 667-684. 